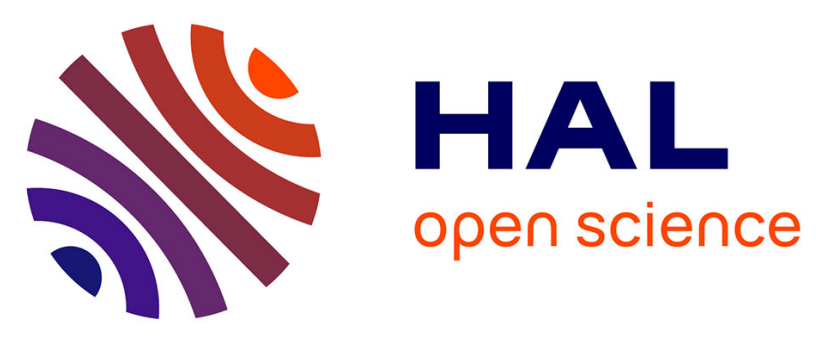

\title{
Enterovirus but not Parvovirus B19 is associated with idiopathic dilated cardiomyopathy and endomyocardial CD3, CD68, or HLA-DR expression
}

Yohan N'Guyen, François Lesaffre, Damien Metz, Sophie Tassan, Yves Saade, Camille Boulagnon, Paul Fornes, Fanny Renois, Laurent Andreoletti

\section{To cite this version:}

Yohan N'Guyen, François Lesaffre, Damien Metz, Sophie Tassan, Yves Saade, et al.. Enterovirus but not Parvovirus B19 is associated with idiopathic dilated cardiomyopathy and endomyocardial CD3, CD68, or HLA-DR expression. Journal of Medical Virology, 2016, 89 (1), pp.55 - 63. 10.1002/jmv.24600 . hal-03267030

\section{HAL Id: hal-03267030 \\ https://hal.science/hal-03267030}

Submitted on 30 Jun 2021

HAL is a multi-disciplinary open access archive for the deposit and dissemination of scientific research documents, whether they are published or not. The documents may come from teaching and research institutions in France or abroad, or from public or private research centers.
L'archive ouverte pluridisciplinaire HAL, est destinée au dépôt et à la diffusion de documents scientifiques de niveau recherche, publiés ou non, émanant des établissements d'enseignement et de recherche français ou étrangers, des laboratoires publics ou privés. 


\section{Basic science paper}

Research article

\section{Journal of Medical Virology}

\section{Enterovirus but not Parvovirus B19 is associated with idiopathic Dilated cardiomyopathy and endomyocardial CD3, CD68 or HLA-DR expression. Revised version R1.}

Short title: Virus \& inflammatory marker detection in DCM.

\section{(3937 words)}

Yohan N'Guyen ${ }^{1-2^{*}}$, François Lesaffre ${ }^{2-3}$, Damien Metz ${ }^{3}$, Sophie Tassan ${ }^{3}$, Yves Saade $^{4}$, Camille Boulagnon ${ }^{5-6}$, Paul Fornes ${ }^{5-6}$, Fanny Renois ${ }^{1-2}$, Laurent Andreoletti ${ }^{1-2}$

\footnotetext{
${ }^{1}$ Laboratoire de Virologie médicale et moléculaire, Centre hospitalier universitaire de Reims, France

${ }^{2}$ EA-4684 Cardiovir, Faculté de médecine, Université de Reims Champagne-Ardenne, Reims, France

${ }^{3}$ Service de Cardiologie, Centre hospitalier universitaire de Reims, France

${ }^{4}$ Service de Chirurgie Thoracique, Centre hospitalier universitaire de Reims, France

${ }^{5}$ Laboratoire d'Anatomie Pathologique, Faculté de médecine, Université de Reims Champagne Ardennes, Reims, France

${ }^{6}$ Laboratoire d'Anatomie Pathologique, Centre hospitalier universitaire de Reims, France *corresponding author: Laboratoire de Virologie médicale et moléculaire, Centre hospitalier universitaire de Reims, Avenue du Général Koenig, 51100 Reims. Tel (+33)326789422 Fax (+33)326784090 mail: yohan.nguyen@wanadoo.fr
} 
Abstract: (198 words)

Background: We assessed Enterovirus (EV) \&Parvovirus B19 (PVB19) genomes and CD3, CD68\&HLA-DR detection in dilated cardiomyopathies (DCM).

Methods: EV\&PVB19 genomes and CD3, CD68\&HLA-DR were detected by PCR and immunohistochemistry assays in 115 endomyocardial biopsies obtained in 13 idiopathic DCM (iDCM) and 10 explained DCM (eDCM) patients. Results were compared with those of 47 atrial surgical samples (47 surgery controls) and 22 autoptic cardiac samples (11 healthy heart controls) (2008-2014, Reims, France).

Results: EV was detected in $23.1 \%$ of iDCM patients but not in eDCM and controls $(P=0.003)($ viral load 803 copies/ $\mu$ g). PVB19 was detected in $76.9 \%, 80.0 \%, 63.6 \%$ and $78.2 \%$ of iDCM, eDCM, healthy heart and surgery controls $(P=0.99)$ with a mean viral load of 413, 346, 1428 and 71 copies/ $\mu$ g. CD3, CD68 or HLA-DR were detected in 100 and 50\% of EV and PVB19 "mono-infected" iDCM patients.

Conclusion: EV was exclusively detected in iDCM cases in association with CD3, CD68 or HLA-DR indicating that EV could be an etiological cause in a subset of iDCM cases. By contrast the equal frequent detection of PVB19 in iDCM cases and controls without association with CD3, CD68 or HLA-DR suggested that PVB19 could be a bystander in many DCM cases.

Keywords: Dilated cardiomyopathy; Enterovirus; Parvovirus B19; Inflammatory markers 


\section{Introduction:}

Dilated cardiomyopathy (DCM) is a common form of heart muscle disease characterized by ventricular chamber enlargement and systolic dysfunction with normal left ventricle wall thickness. Prevalence is estimated to 1:2500 and it is the most frequent cause of heart transplantation in developed countries [Maron et al., 2006]. DCM is acquired in 65 to $80 \%$ of cases and can occur in a wide range of systemic diseases [Maron et al., 2006]. Interestingly, epidemiological studies have evidenced that DCM was related to the evolution of myocarditis in $10 \%$ of cases [Felker et al., 2000].

In developed countries, common viruses are recognized as an important cause of myocarditis and subsequently of DCM cases [Feldman and Mc Namara, 2000; Kühl et al., 2005]. The three main common viruses detected in DCM heart samples were human parvovirus B19 (Family Parvoviridae, genus Erythrovirus species Parvovirus B19 subsequently noticed as PVB19), Human Herpes virus 6 (Family Herpes viridae, genus Roseolovirus species Human Herpes virus 6 subsequently noticed as HHV6) and human enteroviruses (Family Picornaviridae, genus Enterovirus subsequently noticed as EV) in 51, 21 and $9 \%$ of cases, respectively in a large German study using polymerase chain reaction (PCR) [Kühl et al., 2005]. Several studies evidenced EV detection in idiopathic DCM samples in up to $35 \%$ and $75 \%$ of heart samples by viral genome and viral proteins detections, respectively [Lévêque et al., 2012; Li et al., 2000]. Previous experimental data reported that the path from enteroviral myocarditis to DCM was presumed to be due in humans to persistent infection with 5 'Nucleotid terminal deleted EV, leading to low expression of viral protease 2A, the cleavage of dystrophin and the development of DCM [Kim et al., 2005; Hunziker et al., 2007; Badorff et al., 1999; Xiong et al., 2007]. On the opposite, the path from PVB19 myocarditis to DCM was presumed to be due to an ischemic mechanism and endothelial dysfunction [Tschöpe et al. 2005]. Concerning HHV6, its implication in fulminant 
myocarditis was clearly evidenced in immune-competent patients [Ashrafpoor et al., 2013; Lévêque et al., 2011; Chang YL et al., 2009], but the impact of HHV6 in the development of DCM remained difficult to interpret because frequent HHV6 genome detection could be linked to its lifelong latency with subclinical reactivations that sometimes could play a role in heart failure as suggested by recent data [Kühl et al., 2015]. In all cases, common viruses like EV, PVB19 and HHV6 could generate myocardial inflammation, whose detection between 10 and $60 \%$ of DCM has validated the concept of inflammatory cardiomyopathy, defined by the association of histopathological or immunohistological evidence for myocarditis and cardiac dysfunction [Caforio et al., 2013; Noutsias et al, 1999; Agüero et al., 2008; Kindermann et al., 2008; Kühl et al., 2003; Bock et al., 2010].

In the present time even with the help of quantitative viral genomes detection, the frequent detection of viral genome in idiopathic DCM and also in DCM of other etiological origins raised the question whether common viruses could be causative agents or cofactors in the development of DCM cases or innocent bystanders [Bock et al., 2010; Nguyen et al, 2012; Andréoletti et al, 2000]. This question remained definitively unsolved because the current American Heart Association (AHA) and European Society of Cardiology (ESC) indications for endomyocardial biopsies (EMB), which are the sole heart samples available in DCM patients before heart graft, have drastically limited the performance of large scale epidemiological studies including both idiopathic DCM patients and patients suffering from etiologically documented DCM cases (explained DCM cases) [Cooper et al., 2007]. Moreover, the absence of negative controls in previous studies did not allow evaluating the impact of common human viruses onto the development of DCM [Kühl et al., 2005; Kindermann et al., 2008].

In the present report, we investigated the role of common human viruses like EV and PVB19 onto the development of DCM by assessing a potential association between viral 
genomes detection, inflammatory markers detection at the time of clinical diagnosis of DCM using standardized Real-Time PCR and immuno-histological analyses in prospectively collected heart samples: (i) EMBs from idiopathic DCM patients to evaluate the role of viruses as causative agent of DCM; (ii) EMBs from patients with etiologically documented DCM to evaluate the role of viruses as cofactor in development of DCM; (iii) control samples including autoptic heart samples taken from healthy hearts controls and right atrium tissues sampled in patients during extracorporeal circulation (diseased heart without DCM) that were used to evaluate bystander viral detection rates. 


\section{Methods:}

\section{Patients:}

Between 2008 and 2014, Endomyocardial biopsies (EMB) were performed in Reims University Hospital (France) according to AHA and ESC guidelines in 23 patients suffering from $\mathrm{DCM}$ (sex ratio $\mathrm{M} / \mathrm{F}=2.28$, mean age $47.4 \pm 12.9$ years) with a 2 year mean follow up [Cooper et al., 2007]. For each of these patients, serum was prospectively collected and 3 right-sided heart fragments were sampled, formalin-fixed and paraffin-embedded (FFPE) whereas 2 right-sided fragments were immediately flash-frozen in liquid nitrogen and pooled for virological analyses [Cooper et al., 2007]. Patients were then classified as suffering from idiopathic DCM ( $n=13$, sex ratio $M / F=2.25$, mean age $47.5 \pm 11$ years) (iDCM) or as suffering from explained DCM ( $\mathrm{n}=10$, sex ratio $\mathrm{M} / \mathrm{F}=2.33$, mean age $47.3 \pm 15.9$ years) (eDCM) by 2 external reviewers (YNG and FL) taking into account all previous medical history, biological investigations, clinical evolution and further virological and immunohistological analyses (see below). Briefly, DCM was considered as idiopathic (iDCM) in the absence of coronary artery or cardiac rhythm diseases, onset during/immediately after pregnancy, excessive alcohol anthracycline or cardiotoxic exposure, systemic diseases or a positive familial history suggesting familial DCM [Maron et al., 2006]. In any of these cases, DCM was considered as etiologically documented or explained (eDCM). The Hospital Ethics Committee approved the study, and informed consent was obtained from each of the DCM patients (see below). Our investigations conformed to the ethical guidelines of the 1975 Declaration of Helsinki.

DNA and RNA extraction: DNA and RNA were extracted from frozen samples dedicated to virological analyses using NucliSens EasyMag (Biomerieux®) according to manufacturer's instructions [Nguyen et al, 2012].

Viral genome detection: Enteroviruses (EV) and all Human Herpes virus (HHV) were 
detected by PCR assays coupled to microarray hybridization analyses (Clart Entherpex V8.0; Genomica, Madrid, Spain) [Leveque et al, 2011]. Briefly, as described by the manufacturer this PCR assay system coupled to microarray hybridization analyses was capable to detect human EV (EV A-D) in biopsies via amplification of a fragment located between 106- 328 bp (not shown), which is a highly conserved region in all EV types and located further away from all previously known 5'terminally deleted persistent viral forms previously described in murine or human cardiac tissues [Kim et al., 2005; Chapmann et al., 2008]. The sensitivity and the reproducibility of the RT-PCR assay coupled to microarray hybridization analyses were determined using serial 10-fold dilutions of the Coxsackie Virus B3 Nancy strain RNA transcripts produced using wild-type and 5' Terminally Deleted 50 nucleotides (TD-50) Coxsackie Virus B3 clones kindly provided by N. M. Chapman (University of Nebraska Medical Center, Omaha, NE) [Kim et al., 2005]. The two serial dilutions of wild type and TD50 RNA transcripts were ranging from $10^{6}$ to 10 copies diluted in RNA extracts of EVnegative human cardiac tissues. The threshold of viral RNA detection was found to be 10 copies per well for both wild type (full length) and TD CVB3 RNA transcripts (not shown). Human parvovirus B19 (PVB19) were detected using specific real-time PCR assays (Argene Biomérieux ${ }^{\circledR}$, Varhiles, France) according to manufacturer's instruction. Viral loads of EV positive samples using PCR assays coupled to microarray hybridization analyses were quantified using specific real-time PCR assays (Argene Biomérieux®, Varhiles, France). EV quantitative detection threshold of real-time PCR assays was estimated to 50 copies/ $\mu \mathrm{g}$ in our study setting (not shown). All analyses were performed in duplicate.

Histopathological analyses and inflammatory markers detection: The presence of myocarditis was sought out in each FFPE sample after Hematoxylin and Eosin staining (HE staining), according to Dallas Criteria [Aretz et al., 1987]. CD3 (rabbit polyclonal, 1/200, Dako), CD68 (mouse monoclonal, clone KP1, 1/400, Dako) and HLA DR (mouse 
monoclonal, clone TAL.1B5, 1/40, Dako) immuno-staining were performed on $4 \mu \mathrm{m}$ thick FFPE sections of each sample using BenchMark XT automated slide stainer for all antibodies (Ventana Medical System). After deparaffinization, the FFPE sections were incubated with the Cell Conditioner 1 (EDTA, pH 8,4) for $64 \mathrm{~min}$, followed by preprimary peroxidase inhibition and incubation with primary antibodies at $37^{\circ}$ for $32 \mathrm{~min}$. The staining reaction was performed using the ultraView Universal DAB v3 Kit (Ventana Medical System). Because CD3 CD68 and HLA DR immunostaining interpretation criteria were not consensually established and could differ between myocarditis and inflammatory cardiomyopathies [Caforio et al., 2013; Kindermann et al., 2008; Richardson et al., 1996; Kuhn et al., 1996] EMBs were considered in the present report to be positive for inflammatory markers detection after detection of any leukocyte using CD3 or CD68 immunohistochemical assays or after detection of an enhanced expression of HLA class II molecules.

\section{Controls:}

To assess the impact of common viruses on the physiopathological development or evolution of DCM, we performed virological and immuno-histological analyses on additional heart samples of patients without DCM (Figure 1).

All virological and histological results of DCM patients group were compared to those obtained from two large cardiac samples (one left and one right) taken from 11 healthy heart controls (sex ratio $\mathrm{M} / \mathrm{F}=4.5$, mean age $36.4+/-11.1$ years) who died from intoxication or traumatic accident and who were autopsied at Reims University Hospital. Virological and histopathological analyses were performed in heart samples as described for DCM patients (see above). 
EV, HHV and PVB19 genomic detection results of DCM patients group were compared to those obtained from a single right atrium tissue taken from patients during extracorporeal circulation (surgery controls). Patient authorized consent was not required because this tissue is considered as a surgery waste. Forty seven right atrium tissues taken from 47 patients (sex ratio $\mathrm{M} / \mathrm{F}=4.22$, mean age $68.2 \pm 10.2$ years) were screened for the presence of $\mathrm{EV}, \mathrm{HHV}$ and PVB19 genomes using PCR assays coupled to microarray hybridization analyses (Clart Entherpex V8.0; Genomica, Madrid, Spain) and specific real-time PCR assays (Argene Biomérieux ${ }^{\circledR}$ Varhiles, France) as previously described for DCM patients (see above). Surgery controls were classified as heart valve surgery controls or aorto-coronary bypass surgery controls (Figure 1). Patients experiencing combined surgery with both aorto-coronary bypass and valve replacement were classified as aorto-coronary bypass surgery controls.

\section{Statistics:}

Qualitative variables definite as percentage were compared using Fischer exact test or Pearson's Chi-square test, as appropriate. Quantitative variables were compared using Mann Whitney U test. A p value $<0.05$ was considered as significant. Statistical analyses were performed using Stat view 5.0 software (SAS institute). 


\section{Results:}

\section{Viral genome detection:}

As shown in Table I, EV, PVB19, HHV6, HHV4, HHV7 or HHV1 genomes were identified in $84.6 \%(11 / 13), 80 \%(8 / 10), 100 \%(11 / 11)$ and $85.1 \%(40 / 47)$ of iDCM, eDCM, healthy heart and surgery control groups, respectively. Viral genome detection was negative in all serum samples of DCM patients excluding blood contamination (viraemia) of EMBs at the time of EMB sampling (not shown).

EV genome was detected in $23.1 \%$ (3/13) of iDCM patients but not in eDCM, healthy heart and surgery controls $(P=0.003)$ (Figure $2 \mathrm{~A})$. EV viral load was 803 copies $/ \mu$ g for the sole patient with quantifiable EV viral load using real-time PCR assays. The two latter iDCM patients were only positive for EV using PCR assays coupled to microarray hybridization analyses and could not be properly quantified by real-time PCR assays. Estimated EV viral loads for these two patients were between 10 and 50 copies/ $\mu$ g according to Clart Entherpex ${ }^{\circledR}$ and Argene Biomérieux ${ }^{\circledR}$ assays'detection thresholds.

PVB19 genome was detected in 76.9\% (10/13), 80\% (8/10), 63.6\% (7/11) and 78.2\% (37/47) of iDCM, eDCM, healthy heart and surgery control groups $(P=0.99$ for all performed inter-group comparisons) (Figure 2A). Mean PVB19 viral loads were: 413, 346, 1428 and 71 copies/ $\mu$ g in iDCM, eDCM healthy heart and surgery control groups (Figure 2B). All performed inter-group comparisons resulted in non-significant results except for PVB19 viral load in eDCM patients versus PVB19 viral load in all controls groups $(P=0.0048$, according to Mann Whitney U test). Interestingly, PVB19 genome detection rate or viral loads were not statistically different between heart valve surgery controls and aorto-coronary bypass surgery controls $(P=0.99$ and 0.94 respectively). Moreover, PVB19 detection rates were not significantly different between different subgroups of DCM patients or controls (data not 
shown) when statistical analysis was limited to samples with PVB19 viral load> 500 copies/ $\mu$ g, that was the viral load threshold described as clinically relevant for PVB19 induced endomyocardial inflammation [Bock et al., 2010].

HHV DNA was detected in $30.7 \%(4 / 13), 20.0 \%(2 / 10), 63.6 \%(7 / 11)$ and $38.2 \%$ (18/47) of iDCM, eDCM, healthy heart and surgery controls, respectively.

\section{Histopathological analysis and inflammatory markers detection:}

The results of histopathological analyses and inflammatory markers detection assays in DCM patients group and controls (Figure 1) are depicted in Table I. HE staining evidenced absence of myocarditis in all patients groups with available histopathological analyses (iDCM, eDCM, healthy heart controls) except for one patient in the eDCM patients group. A chronic active myocarditis (i.e myocarditis with myocyte necrosis and fibrosis) was evidenced in the EMB of this patient who was suffering from genetic DCM and both PVB19 and HHV6 and HHV4 were detected in this sample. PVB19 viral load was estimated to be below 500 copies/ $\mu \mathrm{g}$ in the endomyocardial tissue of this patient.

Inflammatory markers detection using CD3, CD68 or HLA-DR immunostaining (Figure 3) were positive in $53.8 \%(7 / 13), 60.0 \%(6 / 10)$ and $18.2 \%(2 / 11)$ of iDCM, eDCM and healthy heart control groups respectively (Table I). Cardiac Inflammatory markers were detected in $100 \%(1 / 1)$ of EV positive iDCM patients, $100 \%(2 / 2)$ of co-infected EV and PVB19 iDCM patients and only in 50\% (4/8) of PVB19 "mono-infected" iDCM patients (Table II) $(P=0.19$, according to Fischer exact test, when the detection rate of inflammatory markers was compared between EV positive and negative patients, $100 \%$ (3/3) versus 40\% (4/10) respectively). Among these 4 PVB19 positive iDCM patient samples with positive inflammatory markers detection, only one had a viral load higher than 500copies $/ \mu \mathrm{g}$. No 
patient had cardiac inflammatory detection without viral genome detection in iDCM (Table II) and eDCM patient groups (not shown).

One patient in the eDCM patients group exhibited a CD68 immunohistochemical detection sufficiently intense (>14 cells/mm2) to be interpreted as "inflamed" according to myocarditis and inflammatory cardiomyopathy immunohistochemical criteria [Kindermann et al., 2008]. According to these criteria, no CD3 detection was sufficiently intense to be significant and only 10 out of the 23 DCM patients group fulfilled the criteria of Inflammatory Cardiomyopathy (1 patient with double CD68 and HLA DR detection and 9 patients with HLA DR detection). 


\section{Discussion:}

In the present report, we investigated the role of Enterovirus (EV) and Parvovirus B19 (PVB19) as causative agents, cofactors or bystanders in the development of DCM cases. To this end a serial of unexplained/idiopathic DCM cases (iDCM) were prospectively included at the time of the initial clinical diagnosis that required EMBs according to AHA and ESC guidelines [Cooper et al., 2007]. All the clinical and virological data obtained from these iDCM patients were prospectively compared with those obtained from clinically well-selected DCM or control group patients including etiologically documented DCM cases to assess the role of viruses as cofactor in development of explained DCM (eDCM), and two control groups of patients including healthy heart controls and right atrium tissues sampled in patients during extracorporeal circulation (diseased hearts without DCM; surgery control group) to assess bystander viral detection rates.

\section{Viral genome detection:}

Interestingly we observed that EV genome was exclusively detected among iDCM patients and not in clinically explained DCM (eDCM) patients or controls $(P=0.003)$ and that all these EV positive patients displayed a positive endomyocardial inflammatory markers detection using immunohistological assays. This indicated that EVs were potential causative agents in a subset of DCM cases, here $23 \%$ of study cases, which was consistent with previous studies [Kühl et al., 2005; Lévêque et al., 2012]. Moreover, the low mean EV viral load levels observed in these iDCM patients were consistent with cardiac persistent infections [Lévêque et al., 2012; Nguyen et al, 2012]. The absence of EV genomic detection in 2 out of 3 patients with iDCM using classic Real-Time PCR assays raised the question whether more sensitive techniques like PCR assay coupled to microarray hybridization analyses could be performed to properly investigate the presence of viral genomes in EMB of DCM patients. To increase sensitivity of viral genome detection in a limited number of EMBs sampled in DCM 
patients, our present results suggested that two different molecular techniques should be performed for the detection of common viruses, e.g. Real Time PCR plus PCR coupled to microarray hybridation or PCR coupled to mass spectroscopy analyses [Nguyen et al, 2012].

By contrast, endomyocardial PVB19 DNA detection was positive in more than $60 \%$ of iDCM, eDCM patients and controls (healthy heart and surgery controls). The presence of CD3, CD68 or HLA-DR immunohistochemical positive detection was only associated with $50 \%$ of PVB19 "mono-infected" iDCM patients (Table II). There was no statistically significant difference between PVB19 genome detection rates in iDCM patients group and all other groups (eDCM and controls) (Figure 2A). Among all these groups, PVB19 viral loads were frequently below the threshold described as clinically relevant for the maintenance of endomyocardial inflammation [Bock et al., 2010]. These data suggested that PVB19 could be an innocent bystander in a large subset of iDCM patients. Nevertheless, the apparently statistically significant difference of PVB19 viral load between eDCM patients and controls could be interpreted as a potential cofactor role of PVB19 in the development of explained DCM (Figure 2B). However this difference could also be interpreted as an alpha type I error due to a population bias and the absence of very low PVB19 viral loads $<100$ copies/ $\mu$ g in eDCM patients group, comparatively to controls and mainly surgery controls (Figure 2B). Here, the small effective of our DCM patients that EMBs have been performed according to AHA and ESC indications limited the conclusions that we could draw. In order to increase the number of heart samples for epidemiological studies, we performed EV and PVB19 genomic detection in an original type of heart sample that were right atrium tissues sampled in patients during extracorporeal circulation. This kind of heart sample was necessarily performed at the beginning of extracorporeal circulation and was currently considered as a surgery waste. Patient authorized consent was therefore not required before analyses and right atrium tissue could be an unlimited source of heart samples from patients requiring extracorporeal 
circulation. However, the small size of this right-sided heart sample did not allow to perform both histopathological and virological molecular analyses and to rule out the presence of focal cardiac infection or inflammation [Cooper et al., 2007]. Comparatively to heart valve surgery, we considered the aorto-coronary bypass surgery controls as a proxy of silent myocardial ischemia and we observed that PVB19 genome detection rates and PVB19 viral loads were not statistically different between patients with and without silent myocardial ischemia. This argued against the hypothesis that the path from PVB19 myocarditis to DCM may be due to an ischemic mechanism and these results were consistent with the absence of correlation between Heart Disease clinical phenotype and PVB19 detection [Stewart et al., 2011]. Further largescale studies could be conducted using this new kind of sample.

In the present report, HHV DNA sequences have been evidenced in all DCM cases and controls suggesting a bystander role of these life long persistent viruses. In previous reports of the literature [Ashrafpoor et al., 2013; Lévêque et al., 2011; Chang YL et al., 2009], HHV 6 led to heart failure in immune competent adult through myocarditis, that was easily diagnosed using Dallas Criteria [Aretz et al., 1987]. Such myocarditis was not evidenced in any study patients except one patient with a genetic DCM who had histological myocarditis with endomyocardial detection positive for HHV6, PVB19 and HHV4 DNAs. Taking into account all these data, we did not presume that HHV6 could play a major causative role in the development of DCM in our study.

\section{Histopathological analysis and inflammatory markers detection:}

In this report, the presence of cardiac inflammatory marker defined as the detection of any leukocyte using CD3 or CD68 immunohistochemical assays or the detection of an enhanced expression of HLA class II molecules seemed to discriminate controls from DCM but without any statistically significant difference $(P=0.13)$ (Table I). Because the definitions 
of DCM and inflammatory cardiomyopathy are different but not mutually exclusive [Caforio et al., 2013] and because inflammatory cardiomyopathy is considered as "involved in the development of DCM" [Richardson et al., 1996], we can hypothetize that inflammatory cardiomyopathy immunohistochemical criteria may not be sensible enough to detect all presumed viral induced DCM. More studies are needed to estimate if less restrictive immunohistochemical criteria could not be a better predictor of viral etiology among DCM whose EMBs have been performed late in the course of the disease. In the current setting, both inflammatory cardiac marker and viral genome detection are recommended in EMBs of iDCM patients [Caforio et al., 2013], but only molecular detection of EV, even with low viral loads and without cardiac inflammatory markers, may allow prescription of a broad antiviral treatment like interferon $\beta$. Such a treatment should be prescribed with strong benefits only in EV positive DCM patients, but not in all clinically suspected "viral DCM" cases [Kühl et al., 2003; Kühl et al., 2012]. In the opposite, the frequent detection of PVB19 genome in all kind of patients and controls with viral loads frequently below the threshold described as clinically relevant for PVB19 induced endomyocardial inflammation [Bock et al., 2010], advocated against its role as a potential causative agent of iDCM and against the global usage of potential specific or unspecific antiviral treatments [Stewart et al., 2011]. In case of cardiac inflammatory markers detection, according to myocarditis and inflammatory cardiomyopathy immunohistochemical criteria [Kindermann et al., 2008], without any viral genome detection, an immunosuppressive treatment but not immunoglobulins, could be discussed [Cooper et al., 2007; McNamara et al. 2001].

\section{Study limitations:}

The difficulty to obtain EMBs according to AHA and ESC guidelines [Cooper et al., 2007] in a large number of DCM patients and the impossibility to obtain EMBs in controls patients forced us to make comparisons between different heart samples mainly right-sided in 
different patients (Figure 1) with heterogeneous baseline data available (Table I). However, all samples were handled in the same manner, with respect to type of analysis available in each sample. Even whether we evidenced EV only in 3 out of 13 samples from patients with iDCM using PCR assays coupled to microarray hybridization analysis, we believed we were able to show trends that could not be evidenced in another manner. The impact of right versus left sided biopsies and sampling errors were presumed to be minimal because (i) there was no difference in immunohistochemical analysis and viral genome detection between left and right EMBs [Escher et al., 2014] and (ii) the risk of sampling error was the same for all samples of our study except those of Healthy Heart controls.

In conclusion, EV genome detection was positive and always associated with cardiac inflammatory markers in only $23 \%$ of iDCM patients, whereas the equal frequent detection of PVB19 in $70 \%$ of iDCM, eDCM, healthy heart and surgery control patients was not always associated with the presence of cardiac inflammation markers. These findings suggested that only EV could be an etiological cause in the development of a subset of iDCM cases, whereas PVB19 could be an innocent bystander in a large subset of DCM cases. 
Acknowledgements: We thank Philippe Bourgeois (Argene Biomérieux ${ }^{\circledR}$ ) for his support during virological analyses performed in the present manuscript.

Acknowledgement of Funding: This work was supported by a clinical research grant from the Reims University Medical Centre (grant EA4684-CardioVir).

Competing Interest: The authors report no relationships that could be construed as a conflict of interest. 


\section{References:}

Agüero J, Navarro J, Medina MC, Almenar L, Chirivella M, Martínez-Dolz L, Moro JA, Sánchez-Lazaro I, Ortiz V, Raso R, Salvador A. 2008. Clinical variables associated with the presence of inflammatory infiltrates in patients with dilated cardiomyopathy undergoing heart transplantation. Transplant Proc. 40:3017-9.

Andréoletti L, Bourlet T, Moukassa D, Rey L, Hot D, Li Y, Lambert V, Gosselin B, Mosnier JF, Stankowiak C, Wattré P. 2000. Enteroviruses can persist with or without active viral replication in cardiac tissue of patients with end-stage ischemic or dilated cardiomyopathy. J Infect Dis.182:222-7.

Aretz HT, Billingham ME, Edwards WD, Factor SM, Fallon JT, Fenoglio JJ Jr, Olsen EG, Schoen FJ.1987. Myocarditis: a histopathologic definition and classification. Am J Cardiovasc Pathol.1:3-14.

Ashrafpoor G, Andréoletti L, Bruneval P, Macron L, Azarine A, Lepillier A, Danchin N, Mousseaux E, Redheuil A. 2013. Fulminant human herpesvirus 6 myocarditis in an immunocompetent adult: role of cardiac magnetic resonance in a multidisciplinary approach. Circulation.128:e445-7.

Badorff C, Lee GH, Lamphear BJ, Martone ME, Campbell KP, Rhoads RE, Knowlton KU.1999. Enteroviral protease 2A cleaves dystrophin: evidence of cytoskeletal disruption in an acquired cardiomyopathy. Nat Med. 3:320-6. 
Bock CT, Klingel K, Kandolf R. 2010. Human parvovirus B19-associated myocarditis. N Engl J Med 362:1248-9.

Caforio AL, Pankuweit S, Arbustini E, Basso C, Gimeno-Blanes J, Felix SB, Fu M, Heliö T, Heymans S, Jahns R, Klingel K, Linhart A, Maisch B, McKenna W, Mogensen J, Pinto YM, Ristic A, Schultheiss HP, Seggewiss H, Tavazzi L, Thiene G, Yilmaz A, Charron P, Elliott PM; European Society of Cardiology Working Group on Myocardial and Pericardial Diseases. 2013. Current state of knowledge on aetiology, diagnosis, management, and therapy of myocarditis: a position statement of the European Society of Cardiology Working Group on Myocardial and Pericardial Diseases. Eur Heart J 34:2636-48.

Chang YL, Parker ME, Nuovo G, Miller JB. 2009. Human herpesvirus 6-related fulminant myocarditis and hepatitis in an immunocompetent adult with fatal outcome. Hum Pathol. 40:740-5.

Chapman NM, Kim KS, Drescher KM, Oka K, Tracy S. 2008. 5' terminal deletions in the genome of a coxsackievirus B2 strain occurred naturally in human heart.Virology.375:480-91.

Cooper LT, Baughman KL, Feldman AM, Frustaci A, Jessup M, Kuhl U, Levine GN, Narula J, Starling RC, Towbin J, Virmani R; American Heart Association; American College of Cardiology; European Society of Cardiology; Heart Failure Society of America; Heart Failure Association of the European Society of Cardiology. 2007. The role of endomyocardial biopsy in the management of cardiovascular disease: a scientific statement from the American Heart Association, the American College of 
Cardiology, and the European Society of Cardiology. Endorsed by the Heart Failure Society of America and the Heart Failure Association of the European Society of Cardiology. J Am Coll Cardiol.50:1914-31.

Escher F, Lassner D, Kühl U, Gross U, Westermann D, Poller W, Skurk C, Weitmann K, Hoffmann W, Tschöpe C, Schultheiss HP. 2014. Analysis of endomyocardial biopsies in suspected myocarditis-Diagnostic value of left versus right ventricular biopsy. Int J Cardiol. 177:76-8

Feldman AM, Mc Namara D. 2000. Myocarditis. N Engl J Med 343:1388-98.

Felker GM, Thompson RE, Hare JM, Hruban RH, Clemetson DE, Howard DL, Baughman KL, Kasper EK. 2000.Underlying causes and long-term survival in patients with initially unexplained cardiomyopathy. N Engl J Med 342:1077-84.

Hunziker IP, Cornel CT, Whitton J.L. 2007. Deletions within the 5'UTR of coxsackievirus B3: consequences for virus translation and replication. Virology.360:120-8.

Kim KS, Tracy S, Tapprich W, Bailey J, Lee CK, Kim K, Barry WH, Chapman NM. 2005. 5'-Terminal deletions occur in coxsackievirus B3 during replication in murine hearts and cardiac myocyte cultures and correlate with encapsidation of negativestrand viral RNA. J Virol.79:7024-41. 
Kindermann I, Kindermann M, Kandolf R, Klingel K, Bültmann B, Müller T, Lindinger A, Böhm M. 2008. Predictors of outcome in patients with suspected myocarditis. Circulation.118:639-48.

Kühl U, Pauschinger M, Schwimmbeck PL, Seeberg B, Lober C, Noutsias M, Poller W, Schultheiss HP. 2003. Interferon-beta treatment eliminates cardiotropic viruses and improves left ventricular function in patients with myocardial persistence of viral genomes and left ventricular dysfunction. Circulation.107:2793-8.

Kühl U, Pauschinger M, Noutsias M, Seeberg B, Bock T, Lassner D, Poller W, Kandolf R, Schultheiss HP. 2005. High Prevalence of Viral Genomes and Multiple Viral Infections in the Myocardium of Adults With "Idiopathic" Left Ventricular Dysfunction. Circulation. 111:887-93.

Kühl U, Lassner D, von Schlippenbach J, Poller W, Schultheiss HP. 2012. InterferonBeta improves survival in enterovirus-associated cardiomyopathy. J Am Coll Cardiol.60:1295-6.

Kühl U, Lassner D, Wallaschek N, Gross UM, Krueger GR, Seeberg B, Kaufer BB, Escher F, Poller W, Schultheiss HP. 2015. Chromosomally integrated human herpesvirus 6 in heart failure: prevalence and treatment. Eur J Heart Fail.17:9-19.

Kuhn H, Beer G, Gietzen F. 1996. Definition and classification of cardiomyopathies. Circulation.4:2991-2. 
Leveque N, Van Haecke A, Renois F, Boutolleau D, Talmud D, Andreoletti L. 2011. Rapid virological diagnosis of central nervous system infections by use of a multiplex reverse transcription-PCR DNA microarray. J Clin Microbiol. 49:3874-9.

Lévêque N, Boulagnon C, Brasselet C, Lesaffre F, Boutolleau D, Metz D, Fornes P, Andreoletti L. 2011. A fatal case of Human Herpesvirus 6 chronic myocarditis in an immunocompetent adult. J Clin Virol. 52:142-5.

Lévêque N, Renois F, Talmud D, Nguyen Y, Lesaffre F, Boulagnon C, Bruneval P, Fornes P, Andréoletti L. 2012. Quantitative genomic and antigenomic enterovirus RNA detection in explanted heart tissue samples from patients with end-stage idiopathic dilated cardiomyopathy. J Clin Microbiol. 50:3378-80.

Li Y, Bourlet T, Andreoletti L, Mosnier JF, Peng T, Yang Y, Archard LC, Pozzetto B, Zhang H. 2000. Enteroviral capsid protein VP1 is present in myocardial tissues from some patients with myocarditis or dilated cardiomyopathy. Circulation. 101:231-4.

Maron BJ, Towbin JA, Thiene G, Antzelevitch C, Corrado D, Arnett D, Moss AJ, Seidman CE, Young JB; American Heart Association; Council on Clinical Cardiology, Heart Failure and Transplantation Committee; Quality of Care and Outcomes Research and Functional Genomics and Translational Biology Interdisciplinary Working Groups; Council on Epidemiology and Prevention. 2006. Contemporary definitions and classification of the cardiomyopathies: an American Heart Association Scientific Statement from the Council on Clinical Cardiology, Heart Failure and Transplantation Committee; Quality of Care and Outcomes Research and Functional 
Genomics and Translational Biology Interdisciplinary Working Groups; and Council on Epidemiology and Prevention. Circulation. 113:1807-16.

McNamara DM, Holubkov R, Starling RC, Dec GW, Loh E, Torre-Amione G, Gass A, Janosko K, Tokarczyk T, Kessler P, Mann DL, Feldman AM. 2001. Controlled trial of intravenous immune globulin in recent-onset dilated cardiomyopathy. Circulation.103:2254-9.

Nguyen Y, Renois F, Leveque N, Giusti D, Picard-Maureau M, Bruneval P, Fornes P, Andreoletti L. 2013. Virus detection and semiquantitation in explanted heart tissues of idiopathic dilated cardiomyopathy adult patients by use of PCR coupled with mass spectrometry analysis. J Clin Microbiol.51:2288-94.

Noutsias M, Seeberg B, Schultheiss HP, Kühl U. 1999. Expression of cell adhesion molecules in dilated cardiomyopathy: evidence for endothelial activation in inflammatory cardiomyopathy. Circulation. 99:2124-31.

Richardson P, McKenna W, Bristow M, Maisch B, Mautner B, O'Connell J, Olsen E, Thiene G, Goodwin J, Gyarfas I, Martin I, Nordet P. 1996. Report of the 1995 World Health Organization/International Society and Federation of Cardiology Task Force on the Definition and Classification of Cardiomyopathies. Circulation.93:841-2.

Stewart GC, Lopez-Molina J, Gottumukkala RV, Rosner GF, Anello MS, Hecht JL, Winters GL, Padera RF, Baughman KL, Lipes MA. 2011. Myocardial parvovirus B19 
persistence: lack of association with clinicopathologic phenotype in adults with heart failure. Circ Heart Fail.4:71-8.

Tschöpe C, Bock CT, Kasner M, Noutsias M, Westermann D, Schwimmbeck PL, Pauschinger M, Poller WC, Kühl U, Kandolf R, Schultheiss HP.2005. High Prevalence of Cardiac Parvovirus B19 Infection in Patients With Isolated Left Ventricular Diastolic Dysfunction. Circulation.111:879-86.

Xiong D, Yajima T, Lim BK, Stenbit A, Dublin A, Dalton ND, Summers-Torres D, Molkentin JD, Duplain H, Wessely R, Chen J, Knowlton KU. 2007. Inducible Cardiac-Restricted Expression of Enteroviral Protease 2A Is Sufficient to Induce Dilated Cardiomyopathy. Circulation.115:94-102. 


\section{Legends}

Figure 1 legend: Scheme resuming different study groups according to the initial source of heart samples.

EMBs: Endomyocardial Biopsies. DCM patients: patients suffering from dilated cardiomyopathies (DCM), which were classified in idiopathic DCM patients group (iDCM) and explained DCM patients (eDCM) by 2 external reviewers.

Surgery controls = Heart valve surgery controls + Aorto-coronary bypass surgery controls; Valve surgery controls: Heart valve surgery controls; ACB surgery controls: Aorto-coronary bypass surgery controls.

Longitudinal boxes at the bottom depicting analyses performed in the different study groups. HE: Hematoxylin and Eosin staining, inflammatory markers detection: CD3, CD68 and HLA DR. HHV (Human Herpes viruses), EV (Human Enteroviruses) and PVB19 (Parvovirus B19) genomes detection. 
Figure 2 legend: 2A. Enterovirus (EV) and Parvovirus B19 (PVB19) genomes detection rates in different subgroups of patients. iDCM: idiopathic DCM patients group; eDCM : explained DCM patients group; surgery controls = Heart valve surgery controls + Aorto-coronary bypass surgery controls; Valve surgery controls: Heart valve surgery controls; ACB surgery controls: Aorto-coronary bypass surgery controls. 2B. PVB19 viral loads using real-time PCR assays in DCM patients groups and controls. Plain horizontal line corresponds to mean of each group, whereas grey dashed line corresponds to clinically relevant threshold for the maintenance of myocardial inflammation due to PVB19 [Bock et al., 2010]. All performed inter-group comparisons gave non-significant results, except PVB19 viral load in eDCM patients versus PVB19 viral load in all controls groups.

$* \mathrm{p}<0.005$, according to Fischer exact test or Mann Whitney U test for all comparisons performed (i.e EV genomes detection rate in iDCM patients versus EV genomes detection rates of all others groups and PVB19 viral load in eDCM patients versus PVB19 viral load in all controls groups).

NS: $p=0.99$, according to Fischer exact test, for all comparisons performed (i.e PVB19 genomes detection rate in iDCM patients versus eDCM patients group, PVB19 genomes detection rate in iDCM patients versus all controls groups, PVB19 genomes detection rate in eDCM patients versus all controls groups and PVB19 genomes detection rate in Heart valve surgery controls versus Aorto-coronary bypass surgery controls respectively).

Figure 3 legend: CD3, CD68 and HLA-DR immunohistochemical assays performed in Endomyocardial Biopsies of patients with Dilated Cardiomopathy and autoptic samples of Healthy Heart Controls. Neg: negative, Pos: positive. A\&D: negative and positive HLA-DR assay (magnification X100); B\&E: negative and positive CD68 assay (magnification X200); 
C\&F: negative and positive CD3 assay (magnification X200) respectively. Positive immunostaining in lanes $\mathrm{D}, \mathrm{E} \& \mathrm{~F}$ is depicted by brown points. 